\title{
PENINGKATAN PENGETAHUAN PETANI TERHADAP ADOPSI TEKNOLOGI PERBENIHAN TANAMAN DURIAN
}

\author{
IMPROVEMENT OF FARMER KNOWLEDGE AGAINST \\ ADOPTION OF DURIAN PLANT SEEDING TECHNOLOGY
}

\author{
Rahmat Oktafia $\square$, Wawan Eka Putra dan Miswarti \\ Balai Pengkajian Teknologi Pertanian (BPTP) Bengkulu \\ Corresponding author: covermat212@yahoo.com
}

\begin{abstract}
ABSTRAK
Sosialisasi perbenihan tanaman durian secara vegetatif merupakan salah satu upaya penerapan teknologi mendukung pencapaian produksi benih durian. Dalam akselerasi penerapan inovasi teknologi, pengetahuan petani mempunyai arti penting karena peningkatan pengetahuan petani merupakan tahap awal dalam suatu proses adopsi inovasi teknologi. Pengukuran tingkat pengetahuan responden dilaksanakan pada bulan Oktober 2019 di Desa Kuro Tidur Kecamatan Argamakmur Kabupaten Bengkulu Utara. Metode penyuluhan yang digunakan adalah metode komunikasi langsung melalui sosialisasi dan wawancara menggunakan kuisioner. Jenis data yang digunakan dalam penelitian ini adalah data primer, meliputi karakteristik responden dan tingkat pengetahuan responden terhadap perbenihan tanaman durian. Responden pada penelitian ini adalah petani yang berada di sekitar lokasi berjumlah 20 orang. Analisis kajian ini adalah before-after. Data tingkat pengetahuan petani dianalisis menggunakan statistik deskriptif dan interval kelas. Interval kelas diukur dengan membandingkan hasil pre-test dan post-test. Peningkatan pengetahuan dianalisis dengan menggunakan uji statistik Paired-Sampel T-Test, untuk melihat signifikansinya. Peningkatan pengetahuan petani terhadap perbenihan tanaman durian adalah sebesar $12,08 \%$. Peningkatan pengetahuan petani signifikan dengan nilai 0,003, maka dapat disimpulkan bahwa metode sosialisasi sebagai metode pembelajaran berperan signifikan terhadap peningkatan pengetahuan petani tentang perbenihan tanaman durian. Untuk korelasi atau hubungan karakteristik petani (umur, pendidikan dan pengalaman berusahatani) tidak berhubungan, karena nilai signifikan $>$ dari 0,05 .
\end{abstract}

Kata Kunci : pengetahuan; perbenihan; tanaman; durian

\section{ABSTRACT}

Socialization of the durian plant's vegetative care project is one of the technological applications supporting the production of the durian seed. In acceleration to the application of technological innovation, farmer knowledge has significance because increased farmer knowledge is the first stage in the process of adoption of technological innovation. The survey level of respondents was implemented in October 2019 in the village of Kuro Tidur district Argamakmur district north of bengkulu district. The counseling method used isa direct method of communication through socialization and interviews using the questionnaire. The type of data used in this study is the primary data, including the characteristics of the respondents and the level of respondents' knowledge of the elimination of the durian plant. The respondents on this study were farmers in the vicinity of 20 people. The analysis of this study is postmortem.Data levels of farmers' knowledge are analyzed 
using descriptive statistics and class intervals. Classroom intervals are measured by comparing the results of pre-test and post-test. Increased knowledge was analyzed using statistical tests of t-test samples, to see its significance. Increased farmer knowledge of the durian plant preparation was 12,08\%. Increased farmer knowledge significantly by a value of 0.003, it could be concluded that the method of socialization as a method of learning played a significant role in the increased farmer's knowledge of the durian plant maintenance. For correlation or relationships characteristic of farmers (age, education and economic experience) are unrelated, because of significant value $>0,05$.

Key words: knowledge; ignition; plant; durian

\section{PENDAHULUAN}

Tanaman durian merupakan tanaman asli di kawasan Asia Tenggara yang beriklim tropis seperti Indonesia, Thailand dan Malaysia (Ashari, 2006). Durian menjadi salah satu buah yang mempunyai kelezatan rasa dan kekhasan aroma yang spesifik dan bernilai ekonomi. Sejauh ini durian lokal banyak tumbuh dan memiliki keragaman yang tinggi. Sebagian besar pohon durian yang ada di Indonesia saat ini berasal dari biji (secara generative). Durian (Durio zibethinus Murr) merupakan kekayaan alam yang ditanam dan berkembang di wilayah Indonesia.Durian yang dikenal dengan "The king of the fruit" merupakan buah yang telah lama menjadi unggulan dan kebanggaan berbagai daerah yang memilikinya. Daging buahnya yang bertekstur lunak dengan rasa yang nikmat serta baunya yang khas serta tajam membuat buah yang berduri ini selalu digemari oleh berbagai lapisan masyarakat. Provinsi Bengkulu merupakan salah satu wilayah yang banyak ditemukan sumberdaya genetik durian dan memiliki keragaman yang tinggi (Miswarti, 2017). Berdasarkan data BPS tahun 2012, pohon durian tumbuh dan ditemukan di 10 kabupaten/kota dan pada tahun 2011 produksinya mencapai 331.016 kuintal (BPS Provinsi Bengkulu, 2012). Salah satu jenis durian unggul Bengkulu yang telah dilepas adalah durian Bentara dengan Surat Keputusan Menteri Pertanian Nomor 493/Kpts/SR.120/ 12/2015 (Kementerian Pertanian 2005).

Teknologi perbanyakan benih durian perlu dilakukan untuk melestarikan tanaman durian. Menurut Uji (2005) tanaman akan menghasilkan buah membutuhkan waktu yang cukup lama pada kisaran 7 - 10 tahun, namun dengan perbanyakan vegetatif tanaman durian ini akan berbuah lebih cepat yaitu pada umur 4-5 tahun. Salah satu faktor yang mempengaruhi ialah penerapan teknologi yang rendah. Oleh karena itu perlu cara perbanyakan durian yang dapat menghasilkan bibit varietas unggul untuk menghasilkan produksi tinggi. Upaya 
meningkatkan perbanyakan benih durian, dilakukan berbagai kegiatan antaranya adalah melalui sosialisai penerapan teknologi perbanyakan secara vegetative. Pendekatan dengan sistem penerapan teknologi ini membawa kepada hasil perbanyakan yang seragam dan diketahui kualitas dan kuantitas produksinya. Teknologi ini merupakan inovasi yang telah banyak berkembang namun petani sekitar kegiatan belum banyak mengetahuinya.

Penerapan teknologi yang masih rendah di tingkat petani, berakibat pada rendahnya produktivitas dan pendapatan petani. Penyuluhan pertanian telah diakui sbagai suatu sistem penyampaian informasi dan pemberian nasehat penggunaan input dalam pertanian modern. Penyuluhan adalah proses pendidikan yang bertujuan untuk mengubah kesadaran dan perilaku (pengetahuan, sikap, dan keterampilan) manusia ke arah yang lebih baik sehingga mereka menjadi berdaya dan dapat mencapai kehidupan yang lebih baik dan sejahtera (Mardikanto, 2009), perbaikan teknologi dan sistem budidaya durian melalui peningkatan pengetahuan petani diharapkan dapat meningkatkan produktivitas yang pada akhirnya meningkatkan pendapatan petani. Peningkatan perilaku petani melalui peningkatan pengetahuan, sikap, dan keterampilan merupakan salah satu strategi untuk mempercepat transfer teknologi pertanian kepada pengguna. Dalam akselerasi penerapan inovasi teknologi, pengetahuan petani mempunyai arti penting karena peningkatan pengetahuan petani merupakan tahap awal dalam suatu proses adopsi inovasi teknologi. Peningkatan pengetahuan petani dalam teknologi perbanyakan benih durian dapat melahirkan sikap positif terhadap teknologi yang didiseminasikan dan pada akhirnya dapat memperbaiki keterampilan petani dalam menerapkan inovasi teknologi yang didiseminasikan (Sudarta, 2005). Melalui peningkatan pengetahuan, transfer teknologi diharapkan dapat lebih cepat sampai ke pengguna. Hal ini sangat erat kaitannya dengan kegiatan penyuluhan dan faktor sumberdaya manusianya. Kemampuan seseorang dalam mempelajari sesuatu berbeda-beda. Demikian pula tahap perkembangan mentalnya, keadaan lingkungan dan kesempatannya. Oleh karena itu, perlu dipilih metode penyuluhan pertanian yang berdaya guna dan berhasil guna yang dapat berfungsi sebagai proses penyebarluasan informasi, penerangan atau memberikan penjelasan, perubahan perilaku, dan pendidikan (Saadah, et al. 2011). Kegiatan pengkajian ini bertujuan untuk mengetahui peningkatan pengetahuan petani melalui sosialisasi inovasi teknologi perbenihan 
tanaman durian dalam upaya komunikasi langsung melalui sosialisasi pengembangan benih durian di Provinsi Bengkulu dan untuk mengetahui korelasi antara umur, pendidikan dan tanggungan keluarga petani terhadap peningkatan pengetahuan.

\section{METODE PENELITIAN}

Pengkajian ini dilaksanakan pada bulan Oktober 2019 di Desa Kuro Tidur Kecamatan Argamakmur Kabupaten Bengkulu Utara. Pemilihan lokasi dilakukan secara sangaja (purposive) karena lokasi merupakan daerah yang memiliki durian lokal unggul. Metode penyuluhan yang digunakan adalah metode dan wawancara menggunakan kuisioner. Jenis data yang digunakan dalam penelitian ini adalah data primer, meliputi karakteristik responden dan tingkat pengetahuan responden terhadap teknologi perbanyakan benih durian. Responden pada penelitian ini adalah petani yang berada di Kecamatan Argamakmur Kabupaten Bengkulu Utara, yang dipilih secara sengaja (purposive) yaitu berjumlah 20 orang. Metode pengambilan sampel dilakukan dengan cara sebelum dan setelah sosialisasi (before-after). Karakteristik responden yang dikaji adalah umur, pendidikan, dan pengalaman berusahatani (Tabel 1).

Tabel 1. Karakteristik Petani berdasarkan Umur, Pendidikan, dan Pangalaman Berusaha Tani

\begin{tabular}{llccc}
\hline No. & Karakteristik & $\begin{array}{c}\text { Kelompok } \\
\text { (tahun) }\end{array}$ & $\begin{array}{c}\text { Jumlah } \\
\text { Responden }\end{array}$ & Jumlah (\%) \\
\hline 1. & Umur & $19-63$ & 20 & 100 \\
\hline 2. & Pendidikan & 3 & 1 & 5 \\
& & 6 & 4 & 20 \\
& 9 & 4 & 35 \\
& 12 & 7 & 20 \\
\hline 3. & Pengalaman berusahatani & 16 & 4 & 20 \\
\hline & & $>10$ & 15 & 75 \\
& & $>21-20$ & 3 & 5 \\
& & $>31-40$ & 1 & 5 \\
\hline
\end{tabular}

Sumber : Data primer diolah tahun, 2019.

Data pengetahuan responden

terhadap perbenihan tanaman durian Rumus Index \% $=$ Total Skor $/ \mathrm{Y}$ x 100 dihitung dengan menggunakan rumus Keterangan : index \% (Agustina, 2017):

$\mathrm{Y}=$ Skor tertinggi $\mathrm{x}$ jumlah responden 
Metode analisis penelitian ini adalah before-after. Data tingkat pengetahuan petani dianalisis menggunakan statistik deskriptif dan interval kelas. Interval kelas diukur dengan membandingkan hasil pretest dan post-test. Analisis data peningkatan pengetahuan petani sebelum dan sesudah dilaksanakan sosialisasi dilakukan melalui pengujian dengan menggunakan Uji Statistik Paired Sample T-Test berdasarkan Riduwan dan Alma (2009). Peningkatan pengetahuan dianalisis dengan menggunakan uji statistikPaired-Sampel T-Test, untuk melihat signifikansinya.

Pedoman pengambilan keputusan dalam Uji Paired Sample T-Test berdasarkan nilai signifikan dengan SPSS 16. Jika nilai probabilitas atau Sig. (2tailet $<0,05$, maka terdapat perbedaan yang signifikan antara hasil belajar pada data pre-test dan post-test yang artinya terdapat peranan penggunaan metode

\section{HASIL DAN PEMBAHASAN}

Hasil pengkajian menunjukkan bahwa usia petani secara keseluruhan termasuk pada usia produktif yaitu umur 19-63 tahun sebanyak 20 orang (100\%). Menurut Rusli (2012), tenaga kerja produktif adalah orang yang berada pada rentang umur 15-64 tahun. Dominasi tingkat pendidikan petani adalah Sekolah Menengah Pertama yaitu sebanyak 35\%. evaluasi terhadap strategi sosialisasi dalam meningkatkan pengetahuan peserta yang merupakan petugas petani. Sebaliknya, jika nilai probabilitas atau Sig. (2-tailet) > 0,05 , maka Tidak terdapat perbedaan yang signifikan antara hasil belajar pada data pre-test dan post-test yang artinya tidak ada peranan kegiatan sosialisasi dalam meningkatkan pengetahuan peserta yang merupakan petani.

Analisis korelasi merupakan studi pembahasan tentang derajad keeratan hubungan antar variabel yang dinyatakan dengan koefisien korelasi. Hubungan antara variabel bebas (x) dan variabel terikat (Y). Kekuatan korelasi linear antar variabel $\mathrm{X}$ dan variabel $\mathrm{Y}$ disajikan dengan rxy didefinisikan dengan rumus seperti di bawah ini (Sugiyono, 2011) :

$$
r_{x y}=\frac{N \sum X Y-\sum X \sum Y}{\sqrt{N \sum X^{2}-\left(\sum X\right)^{2}} \cdot \sqrt{N \sum Y-\left(\sum Y\right)^{2}}}
$$

Umur dan pendidikan formal sangat mempengaruhi tingkat perilaku seseorang dalam pengambilan keputusan. Tingkat pendidikan mempengaruhi pola pikir, keterampilan, sikap dan pengambilan keputusan dan tingkat pendidikan juga sangat mempengaruhi dalam menerima informasi (Nazariah, 2015). Semakin tinggi pendidikan seseorang semakin cepat pula yang bersangkutan menerima 
informasi. Dengan kata lain, pendidikan formal yang cukup dari responden mengindikasikan bahwa responden termasuk dalam kategori yang cukup cepat dalam menerima informasi. Umur produktif dengan tingkat pendidikan tinggi memungkinkan petani menjadi lebih dinamis dan lebih mudah menerima inovasi baru. Soekartawi (1988 )menyatakan bahwa mereka yang berpendidikan tinggi relatif cepat dalam melaksanakan adopsi teknologi, begitu juga sebaliknya mereka yang berpendidikan rendah relatif agak sulit untuk melaksanakan adopsi inovasi dengan cepat. Jika pengetahuan petani tinggi dan petani bersikap positif terhadap suatu teknologi baru di bidang pertanian, maka penerapan teknologi tersebut akan menjadi lebih sempurna, yang pada akhirnya akan memberikan hasil secara lebih memuaskan baik secara kuantitas maupun kualitas (Sudarta, 2005).

Pengalaman juga berperan dalam peningkatan pengetahuan seseorang. Responden pada kegiatan sosialisasi perbanyakan benih durian ini memiliki pengalaman berusahatani yang paling dominan adalah mulai dari 1-10 tahun sebanyak $75 \%$. Dengan adanya pengalaman berusahatani diharapkan penerapan teknologi perbanyakan benih durian yang didiseminasikan menjadi lebih mudah menjadi lebih sempurna, yang pada akhirnya akan memberikan hasil secara lebih memuaskan baik secara kuantitas maupun kualitas (Sudarta, 2005).

\section{Tingkat Pengetahuan Petani terhadap} Teknologi Perbanyakan Benih Durian

Pengetahuan petani terhadap teknologi perbanyakan benih duriandilihat dari 12 pernyataan dapat dilihat pada Tabel 2.

Peningkatan pengetahuan petani setelah sosialisasi diukur dengan membandingkan hasil pre-test dan post-test.Hasil kajian menunjukkan bahwa peningkatan pengetahuan petani setelah sosialisasi ratarata $12,08 \%$. Dapat dilihat juga bahwa tingkat pengetahuan petani sebelum sosialisasi sudah cukup tinggi, ini dapat dilihat di tabel kolom sebelum sosialisasi yaitu $66,25 \%$.

Sedangkan hasil uji paired sample t-test dapat di Interpretasi dalam dua output yaitu dapat dilihat pada Tabel 3 dan Tabel 4. 
Tabel 2.Tingkat Pengetahuan Petani terhadap Teknologi Perbanyakan Benih Durian Dlihat dari 12 Pertanyaan

\begin{tabular}{|c|c|c|c|c|}
\hline No. & Pertanyaan & $\begin{array}{l}\text { Sebelum } \\
\text { Sosialisasi } \\
\quad(\%)\end{array}$ & $\begin{array}{l}\text { Sesudah } \\
\text { Sosialisas } \\
\quad \text { i }(\%)\end{array}$ & $\begin{array}{l}\text { Perubahan } \\
\text { tingkat } \\
\text { pengetahuan } \\
(\%) \\
\end{array}$ \\
\hline 1 & $\begin{array}{l}\text { Varietas yang telah dilepas oleh pemerintah baik berupa } \\
\text { varietas baru maupun varietas lokal yang mempunyai } \\
\text { kelebihan dalam potensi hasil dan/atau sifat-sifat lainnya } \\
\text { disebut: }\end{array}$ & 95,0 & 95,0 & 0 \\
\hline 2 & $\begin{array}{l}\text { Pengembangan tanaman durian diperlukan benih unggul. } \\
\text { Kesalahan dalam penggunaan benih durian akan } \\
\text { mengakibatkan kerugian yang besar karena baru dirasakan } \\
\text { setelah tanaman berbuah. Benih yang benar kecuali adalah }\end{array}$ & 60,0 & 75,0 & 15 \\
\hline 3 & $\begin{array}{l}\text { Perbanyakan durian dilakukan secara generatif dan vegetatif. } \\
\text { Untuk mendapatkan benih yang sama dengan induknya dapat } \\
\text { dilakukan dengan cara perbanyakan }\end{array}$ & 10,0 & 50,0 & 40 \\
\hline 4 & $\begin{array}{l}\text { Perbanyakan tanaman durian yang diperbanyak dengan } \\
\text { vegetatif }\end{array}$ & 80,0 & 90,0 & 10 \\
\hline 5 & $\begin{array}{l}\text { Faktor yang mempengaruhi keberhasilan penyambungan } \\
\text { antara lain }\end{array}$ & 95,0 & 100,0 & 5 \\
\hline 6 & $\begin{array}{l}\text { Varietas lokal durian yang telah dilepas ke Kementerian } \\
\text { berasal dari Bengkulu }\end{array}$ & 55,0 & 65,0 & 10 \\
\hline 7 & $\begin{array}{l}\text { Durian varietas lokal yang telah didaftarkan Ke Kementerian } \\
\text { Pertanian melalui PPVTPP sebagai asset pemerintah } \\
\text { Kabupaten Bengkulu Utara adalah : }\end{array}$ & 10,0 & 15,00 & 5 \\
\hline 8 & $\begin{array}{l}\text { Tanah yang digunakan untuk membuat media tanam } \\
\text { perbenihan durian adalah }\end{array}$ & 65,0 & 80,00 & 15 \\
\hline 9 & Syarat tanaman yang akan dijadikan batang bawah antara lain & 80,0 & 90,00 & 10 \\
\hline 10 & $\begin{array}{l}\text { Syarat tanaman yang akan dijadikan sebagai batang atas } \\
\text { sebagai berikut: }\end{array}$ & 65,0 & 90,0 & 25 \\
\hline 11 & $\begin{array}{l}\text { Keberhasilan sambungan dicirikan mata tempel berwarna } \\
\text { hijau. Langkah selanjutnya adalah: }\end{array}$ & 85,0 & 95,0 & 10 \\
\hline \multirow[t]{2}{*}{12} & $\begin{array}{l}\text { Pemeliharaan benih durian yang umum dilakukan untuk } \\
\text { pembenihana adalah: }\end{array}$ & 95,0 & 95,0 & 0 \\
\hline & Tingkat pengetahuan rata-rata & 66,25 & 78,33 & 12,08 \\
\hline
\end{tabular}

Sumber : Data primer 2019.

Tabel 3. Hasil Analisis Statistik (Paired Samples Statistics) Data Pre-test dan Post-test Peningkatan Pengetahuan Petani

\begin{tabular}{llcccc}
\hline & & Mean & N & Std. Deviation & Std. Error Mean \\
\hline Pair 1 & Pretest & 66.25 & 12 & 29.705 & 8.575 \\
& Posttest & 78.33 & 12 & 24.710 & 7.133 \\
\hline
\end{tabular}

Interpretasi dari Tabel 3. rata-rata hasil penilaian sebesar 66,25. memperlihatkan hasil ringkasan statistik dari kedua sampel atau data pre-test dan Sedangkan untuk nilai post-test diperoleh post-test. Untuk nilai pretest diperoleh nilai rata-rata hasil penilaian sebesar 78,33 . 
Tabel 4. Hasil Ringkasan Statistik (Paired Samples Test) Data Pretest dan Posttest Peningkatan Pengetahuan Petani.

\begin{tabular}{|c|c|c|c|c|c|c|c|c|c|}
\hline & & \multicolumn{5}{|c|}{ Paired Differences } & \multirow[b]{3}{*}{$\mathrm{T}$} & \multirow[b]{3}{*}{$\mathrm{df}$} & \multirow{3}{*}{$\begin{array}{l}\text { Sig. (2- } \\
\text { tailed) }\end{array}$} \\
\hline & & \multirow[t]{2}{*}{ Mean } & \multirow[t]{2}{*}{ Std. Deviation } & \multirow[t]{2}{*}{$\begin{array}{l}\text { Std. Error } \\
\text { Mean }\end{array}$} & \multicolumn{2}{|c|}{$\begin{array}{l}95 \% \text { Confidence } \\
\text { Interval of the } \\
\text { Difference }\end{array}$} & & & \\
\hline & & & & & Lower & Upper & & & \\
\hline Pair 1 & $\begin{array}{l}\text { Pretest - } \\
\text { Posttest }\end{array}$ & -12.083 & 11.172 & 3.225 & -19.182 & -4.985 & -3.747 & 11 & .003 \\
\hline
\end{tabular}

Interpretasi dari Tabel 4 diperlihatkan hasil ringkasan statistik dari kedua sampel atau data pretest dan posttest. Terlihat bahwa nilai Sig. (2-tailed) sebesar 0,003 lebih kecil dari 0,05 maka dapat disimpulkan bahwa metode sosialisasi sebagai metode pembelajaran berperanan signifikan terhadap peningkatan pengetahuan petani tentang perbenihan tanaman durian dengan nilai signifikan 0,003 .

Korelasi Umur, Pendidikan, dan Lama Berusahatani dengan Peningkatan Pengetahuan tentang Teknologi Perbanyakan Benih Durian

Dari hasil analisis korelasi dengan menggunakan SPSS 16.0 korelasi spearman umur, pendidikan dan pengalaman berusahatani tidak berhubungan signifikan terhadap peningkatan pengetahuan petani tentang teknologi perbanyakan benih durian yaitu $>0,05$. Peningkatan pengetahuan petani tidak dipengaruhi oleh umur,pendidikan dan pengalaman berusahatani, karena dalam kegiatan sosialisasi diperlukan metode yang tepat serta keseriusan peserta supaya yang disampaikan dalam pertemuan dapat ditangkap secara sempurna oleh peserta.

\section{KESIMPULAN}

Peningkatan pengetahuan petani setelah mengikuti kegiatan sosialisasi tentang teknologi perbenihan tanaman durian rata-rata sebesar $12,08 \%$. Korelasi umur, pendidikan dan pengalaman berusahatani tidak berhubungan signifikan terhadap peningkatan pengetahuan petani tentang perbenihan tanaman durian.

\section{UCAPAN TERIMA KASIH}

Penulis mengucapkan terima kasih kepada Bapak Kepala BPTP Balitbangtan Bengkulu yang telah memberikan arahan dan masukan, serta semua pihak yang telah membantu dalam pelaksanaan pengkajian ini.

\section{DAFTAR PUSTAKA}

Agustina R dan Chandra A. 2017. Analisis Implementasi Game Edukasi "The Hero Diponegoro" Guna Meningkatkan Hasil Belajar Siswa 
di MTS. Attarogie Malang. Jurnal Teknologi Informasi. ISSN 20862989. Vo.8 No.1.

Ashari, S. 2006. Hortikultura Aspek Budidaya. UI Press. Jakarta. 490pp.

Badan Pusat Statistik Provinsi Bengkulu (2012) Provinsi Bengkulu dalam angka.Bengkulu, Badan Pusat StatistikProvinsi Bengkulu.

Kementerian Pertanian(2005)

KeputusanMenteri Pertanian Nomor: 493/Kpts/S.R.120/12/2005 tentang Pelepasan Durian Bentara Sebagai Varietas Unggul. [Online] Tersedia pada: http://perundangan.pertanian.go.id/ admin/k_mentan/SK-493-05.pdf [Diakses 08 Maret 2020].

Mardikanto, Totok. 2009. Sistem Penyuluhan Pertanian. Sebelas Maaret University Press. Solo.

Miswarti, Calista I, Putra W.E, Oktafia R, Artanti H, Zainani dan A S H. 2019. Laporan Akhir Pemanfaatan Hasil Eksplorasi Sumberdaya Genik Mangga/Manggis/Durian di Provinsi Bengkulu.

Miswarti, PutraW.E., SugandiD.. 2017. Analisis Keragaman plasma Nutfah Durian di Provinsi Bengkulu Bedasarkan Karakter Morfologi. Buletin Plasma Nutfah.

Nazariah. 2015. Percepatan Difusi Teknologi Ptt Kedelai Di Provinsi
Aceh. Prosiding Seminar Nasional Yang Diselenggarakan Pada Tanggal 24 - 25 Agustus Di Bogor, Temu Teknis Jabatan Fungsional Non Peneliti.Halaman :93-99.

Riduwan dan Alma, B. 2009. Pengantar Statistika Sosial. Alfabeta: Bandung

Rusli S. 2012. Pengantar ilmu kependudukan. Edisi revisi. Jakarta (ID): LP3ES.

Saadah, Sulili A dan Binindra 2011. Peranan Penyuluh Pertanian Terhadap Pendapatan Petani yang Menerapkan Sistem Tanam Jajar Legowo. JA, Volume. 7 No. 2. Halaman : 1-11

Sugiyono. 2011. Statistik Untuk Penelitian. Penerbit Alfabeta Bandung

Sudarta, W. 2005. Pengetahuan dan Sikap Petani Terhadap Pengendalian Hama Tanaman Terpadu (Online). http: //ejournal .unud. ac.id/ abstrak / (6)\%20soca-sudartapks\%20pht(2).pdf diakses 30 Desember 2009.

Soekartawi. 1988. Prinsip Dasar Komunikasi Pertanian. Penerbit Universitas Indonesia. Jakarta.

Uji, T. 2005. Keanekaragaman jenis dan sumber plasma nutfah Durio (Durio sp.) di Indonesia. Bul. Plasma Nutfah 11(1):28-33. 